\title{
Ensino de Ciências e Saúde para Idosos: Uma proposta de construçáo de Cartilha Informativa em Grupos de Convivência
}

\author{
Teaching of sciences and health for senior: \\ a propose of the construction of informative spelling book in groups of coexistence
}

Rosane Marques de Carvalho ${ }^{1,2}$ Rosane Moreira Silva de Meirelles 1,3,4

\section{Resumo}

O envelhecimento humano desperta estudos que visam à ampliação do conhecimento e discussões sobre as experiências do envelhecer permitindo, na educação não formal, adequaçáo do idoso em novas perspectivas na sua própria velhice. Neste trabalho, temos como objetivo principal apresentar, no formato de relato de experiência, uma cartilha educativa com conceitos de ciências, saúde e cidadania. A partir do mapeamento do perfil e das concepçóes sobre o envelhecimento, observadas pelos idosos acima de 60 anos, participantes dos grupos de convivência de Volta Redonda, que engloba um espaço social com diversidade de opiniôes, vivências e cultura, foi elaborado instrumento de avaliação sobre o perfil socioeconômico e, com os resultados dos dados coletados, além de dados bibliográficos, foi elaborado um protótipo da cartilha. Espera-se ampliar as discussóes sobre envelhecimento saudável com idosos e disponibilizar um material alternativo que subsidie na construção da Política do Idoso.

Palavras-chave: Concepçôes; envelhecimento; grupos de convivência; cartilha.

\section{Abstract}

TThe human aging wakes up several studies that it seeks to the amplification of the knowledge and new discussions about the experiences of aging that they allow in the no-formal education, ways to adapt the senior in new perspectives in your own age. In this work we have as main objective to present in the format of report of experience, as an educational spelling book is being elaborated with concepts of sciences, health and citizenship. Starting from the carry out a survey of the profile and of the conceptions on the aging process, observed by the seniors over 60 years old, participants of the groups of coexistence in Volta Redonda city, which is a social space that embraces a rich diversity of opinions, existences and cultures. An evaluation instrument was elaborated about the economical partner profile. Thus, with the collected data results and bibliographical data, was elaborated a prototype with information on health, relationships among people, rights, dignity and self-esteem. It hopes to enlarge the discussions on healthy aging, with seniors and arrange an alternative material that subsidizes in the construction of the Senior's Politics.

Keywords: Conceptions; aging; coexistence groups; spelling book. 


\section{INTRODUÇÃO}

O crescimento do número de idosos no Brasil vem acompanhado pelo aumento da expectativa de vida da população como um todo, que dobrou no período de um século, passando de aproximadamente 34 anos em 1900, para mais de 68 anos, em 2000, com projeçáo de alcançar os 75 anos em 2025, de acordo com os dados de (Veras, 1994). Embora a biologia e a medicina estabeleçam critérios para a definição das etapas da vida, tal classificaçáo varia de uma sociedade para a outra e dentro de uma mesma sociedade, por motivos variados e geralmente relacionados a aspectos sócio-culturais e econômicos, dentre os quais podemos apontar fatores como classe social, gênero, concepçóes sobre sexualidade, relação com o grupo familiar, casamento, trabalho, a percepção corporal, entre outros (Debert, 1994). Nesse sentido, o estudo do processo do envelhecimento inclui saberes multidisciplinares na reflexão sobre o envelhecimento do ser, que pensa sobre si mesmo e sobre suas representaçôes. Das diversas formas de categorização - sociais, culturais, psicológicas que tentam definir o limite entre as idades, nenhuma delas é capaz de descrever o experienciar da velhice, tornando-se vagas arbitrárias generalizaçōes (Dourado e Leibing, 2002). Portanto, os diversos autores não são concordes ao discorrerem a respeito do conceito de velhice.

A Organização Mundial da Saúde (OMS) classifica o envelhecimento em quatro estágios: Meia idade: 45 a 59 anos; Idoso (a): 60 a 74 anos; Anciāo 75 a 90 anos; Velhice extrema: 90 anos em diante. O presente trabalho focou idosos acima de 60 anos, observando que tem sido ponto chave de vários estudos e, já há algum tempo, inserida no conjunto de ciências, técnicas e saberes. De uma perspectiva das Ciências da Saúde, há uma estreita relação entre hábitos de vida saudável, prática regular e prolongada de atividade física, boa nutrição, criação de hábitos saudáveis e manutenção da convivência social, para um bom processo de envelhecimento, como nas discussões de (Carvalho, 2003). Os estudos vêm aumentando substancialmente e de forma rápida dentro da área da Gerontologia, em que novas teorias estão sendo propostas, avaliadas e checadas no intuito de "acrescentar vida aos anos e não apenas anos à vida” (Freire, 2000). Camarano cita que:

Reconhece-se a existência de uma gama bastante ampla de critérios para a demarcação do que venha a ser um "idoso". O mais comum baseia-se no limite etário, como é o caso, por exemplo, da definição da Política Nacional do Idoso (Lei 8.842, de 4 de janeiro de 1994). O Estatuto do Idoso (Lei 10.741, de $1^{\circ}$ de outubro de 2003) endossa essa definição. Já a Organização Mundial da Saúde (OMS) considera como idosas as pessoas com 60 anos ou mais, se elas residem em países em desenvolvimento, e com 65 anos e mais se residem em países desenvolvidos.
Percebemos, então, que o processo de envelhecimento não é dependente de apenas um fator, o biológico, e que desta forma, se aproxima dos atuais conhecimentos da área de estudos da qualidade de vida, que visa, entre outros aspectos, estabelecer os critérios que podem defini-la, com base em saberes multidisciplinares, para o estabelecimento de políticas sociais de saúde. Assim temos, por exemplo, a proposição, pela Organização Mundial de Saúde, do termo "envelhecimento ativo", definido como sendo "o processo de aperfeiçoar oportunidades para a saúde, a participação e a segurança de modo a melhorar a qualidade de vida no processo de envelhecimento de cada pessoa" (OMS, 2002). Alleyne (2001) por sua vez, aponta que "é possivel imaginar que há cinco principais domínios da qualidade de vida: saúde e bem-estar, relaçóes interpessoais, comunidade e moradia, crescimento pessoal, dignidade e autoestima", ou seja, segundo esse autor, existem fatores que podem ser considerados internos e externos às pessoas, da mesma forma que o processo de envelhecimento.

O que se pretende aqui é avançar na direção de se considerar, conjuntamente, tais fatores, partindo-se da premissa de que as etapas da vida, bem como a percepção corporal do processo de envelhecimento, são vivenciadas pelas dimensôes subjetivas e simbólicas da vida social e não apenas pela dimensão biológica. É que muitas políticas sociais para o trato da questão têm apontado para a importância de se considerar a atençáo à saúde do idoso de modo associado aos seus direitos de cidadania e à promoção da qualidade de vida que, como vimos, encontra-se atrelada a múltiplos fatores. $\mathrm{O}$ avanço da ciência, não só prolonga a vida dos doentes, mas cura doenças consideradas graves ou letais. As políticas públicas de vacinação e de imunização, o acesso à informação e a consequente queda na taxa de natalidade nas famílias contribuíram para que ocorresse tal fenômeno na atualidade, ou seja, o mundo está envelhecendo, está se transformando num "mundo idoso".

O Município de Volta Redonda tem sido conhecido e reconhecido, por indicadores de qualidade de vida, por suas políticas sociais direcionadas à populaçáo idosa, nos setores público e privado. No entanto, a população usuária desse programa não foi ainda estudada sob a perspectiva que aqui se propóe - com a proposição de atividades lúdicas voltadas para o ensino de ciências e saúde. Neste trabalho temos como objetivo principal mapear o perfil e apreender as concepçóes sobre o processo de envelhecimento e as etapas da vida entre idosos acima de 60 anos participantes dos grupos de convivência da Secretaria Municipal de Ação Comunitária-SMAC / Volta Redonda.

A partir desses dados, juntamente com uma pesquisa bibliográfica e quantitativa, pretende-se elaborar, com as colocaçóes qualitativas pontuadas pelos próprios idosos, uma 
cartilha para nortear os trabalhos futuros dos dinamizadores e orientar os próprios idosos nos grupos de convivência. Estes idosos se encontram uma vez por semana, por 4 horas, em atividades que são voltadas para o desenvolvimento intelectual e biopsicosocial em uma perspectiva de educação não formal. O número de componentes varia em torno de 50 a 120, com idade de 50 anos acima, totalizando 3900 idosos.

As ações diárias são definidas pelo grupo ao longo do processo. Essa escolha pode ser prévia ou acontecer no próprio encontro, dependendo da necessidade. O técnico pode fazer sugestóes de atividade e temas, ajudar a organizar materiais, sugerir técnicas de dinamização de grupo, conforme as necessidades percebidas no contexto do programa. É importante que o grupo aceite, ainda que parcialmente, essas sugestôes, para que sejam realizadas com proveito. Tais experiências nos motivam a um investimento ainda maior, nas atividades de convivência com os idosos, que busca a restauração de vida no desenvolvimento do convívio geracional e intergeracional, favorece o rompimento com o isolamento, a exclusão social, o fortalecimento da autoestima, o reconhecimento social e a motivação para novos projetos de vida, que nos mostra as variaçóes na conduta do envelhecer destes idosos.

O município realiza programas, projetos e serviços para esta faixa etária em todas as perspectivas como educação, saúde, esporte e lazer, assistência social e geração de renda. Desde já, é importante destacar que a presente pesquisa não pretende avaliar as políticas em questão, mas refletir sobre as concepçóes acerca das etapas da vida e o processo de envelhecimento, através de categorias sociais, de modo a apreender a diversidade de modos através dos quais são percebidos e vivenciados nesses processos. Contudo, não descartamos a possibilidade deste estudo vir a contribuir, de alguma maneira, para o aprimoramento de tais políticas. Por outro lado, pretendemos que os materiais coletados na pesquisa nos subsidiem na construção de uma cartilha que explore o tema, para contribuir com novas visóes do envelhecimento e consequente valorização dos idosos e do próprio envelhecimento.

Por fim, partimos da premissa de que Volta Redonda, município do Estado do Rio de Janeiro, tem um público idoso com uma situação financeira diferenciada, pois em grande parte são aposentados ou pensionistas da Companhia Siderúrgica Nacional, e existe também uma extensão de proventos, pela CBS (Caixa Beneficente da Siderúrgica) que completa seus salários. Debert (1997) mostra que o idoso, especialmente a partir da década de 1980, tornou-se um ator político cada vez mais claro na sociedade brasileira, ocupando espaço na mídia e ganhando a atenção da indústria do consumo, do lazer e do turismo.

O Ministério do Desenvolvimento Social - MDS mostra que estudos recentes também têm apontado para a importância do benefício BPC (Benefício de Prestação Continuada), para os maiores de 65 anos sem renda de aposentadoria ou pensão, recebida pelo idoso para composição da renda familiar. Mas, embora seja um município socialmente marcado pela atividade metalúrgica, a diversidade sóciocultural e econômica pode ser encarada como uma hipótese para o modo diferenciado de se vivenciar socialmente a velhice, para além da dimensão pessoal e subjetiva.

A nossa experiência com idosos se inicia já no estágio da graduação em Educação Física com atuação em asilos. Em 2000 com aulas de hidroginástica e natação para idosos até 200, em 2001, com grupos de convivência na Secretaria de Ação Comunitária - SMAC realizamos atividades sócioeducativas que visam à valorização na promoçáo do envelhecimento dentro Departamento de Proteção Social Básica com a implantação do Sistema Únicas da Assistência Social - SUAS implementando a Política Nacional do Idoso.

\section{O ENVELHECIMENTO DA POPULAÇÁO, PO- LÍTICAS PÚBLICAS E FUNÇÃO SOCIAL}

Desde 1994, está estabelecida a "Política Nacional do Idoso" (Lei 8842 , de 4 de janeiro de 1994), a qual criou normas para os direitos sociais dos idosos, visando garantir a autonomia, integração e participação efetiva na sociedade. Essa lei foi reivindicada pela sociedade, sendo resultado de inúmeras discussóes e consultas, nas quais participaram idosos ativos, aposentados, professores universitários, profissionais da área de gerontologia e geriatria e várias entidades representativas desse segmento, que elaboraram um documento que se transformou no texto base da lei. Em 2003, com a aprovação do "Estatuto do Idoso" (Lei no 10.741, de 01 de outubro de 2003), houve um avanço com relaçáo a direitos dos idosos, os quais já estavam minimamente assegurados na Constituição Federal de 1988, em seu Capítulo VII, Título VIII (Ordem Social), nos artigos 229 e 230, que versa sobre alguns princípios e direitos assegurados a este segmento. Assim, podemos observar que as leis que asseguram princípios e direitos dos idosos existem e precisam ser exigidas como efetivas pela sociedade. É preciso garantir que as leis sejam aplicadas e os casos de não cumprimento, sejam punidos. É essencial que as políticas públicas garantam o cumprimento de tais leis e que os idosos possam passar pelo processo de envelhecimento de forma natural como cidadão inserido na sociedade.

O aumento da população de idosos é um fenômeno mundial tão profundo que muitos chamam de "revolução demográfica”. No último meio século, a expectativa de vida aumentou em cerca de 20 anos. Se forem considerados os 
últimos dois séculos, ela quase dobrou. Conforme pesquisas oficiais, que a seguir passam a ser demonstrado, esse processo está longe do fim. Conforme dados trazidos pelo Instituto Brasileiro de Geografia e Estatística, o envelhecimento é um fenômeno mundial, ou seja, o crescimento da população idosa, em números absolutos e relativos, está ocorrendo em um nível sem precedentes. Em 1950, eram cerca de 204 milhóes de idosos no mundo e, em 1998, ou seja, quase cinco décadas depois, esse contingente alcançava 579 milhóes de pessoas, ou seja, um crescimento de quase 8 milhóes de pessoas idosas por ano. Segundo previsão da ONU, a continuar no ritmo acelerado que se processa o envelhecimento mundial, por volta do ano de 2050, pela primeira vez na história humana, o número de pessoas idosas será maior que o de crianças abaixo dos 14 anos. A população mundial deve saltar dos 6 bilhóes para 10 bilhóes em 2050. No mesmo período, o número de idosos deve triplicar, passando para 2 bilhôes, ou seja, quase 25\% do planeta. (IBGE, 2000)

A expectativa média de vida do brasileiro ao nascer é de 81,3 anos, a mesma da população japonesa nos dias atuais. Além disso, se em 2000 o Brasil tinha 1,8 milhão de pessoas com 80 anos ou mais, em 2050 esse contingente poderá ser de 13,7 milhóes, o que demonstra toda a importância que o idoso terá na sociedade brasileira, com repercussão cada vez maior nas políticas públicas (CAMARANO, 2002). Ao mesmo tempo em que se observa tal realidade mundial e brasileira, conclui-se que há um despreparo muito grande para enfrentá-la e compreendê-la. Não se possui formação numa ótica humanista de respeito e consideração para com o idoso. A cultura, à qual se está inserido, em nossa realidade, é de culto ao corpo, da chamada "juventude eterna" e não há uma formação cultural para o envelhecimento, de compreendê-lo como acontecimento natural da vida, como também não há formação cultural de respeito à dignidade daquelas pessoas que já envelheceram. Também, e como consequência dessa formação voltada para o culto ao corpo e à juventude eterna, nos deparamos, com os alarmantes índices de violência contra o idoso e que esta questão é quase na sua totalidade, doméstica e familiar.

\section{ENSINO NÁOFORMAL: POSSIBILIDADE DE UM ENVELHECER SAUDÁVEL}

Os grupos de convivência dos idosos são espaços de grande oportunidade para a execução da educação nãoformal, possibilita vida longa para uma parcela da população, quando a ciência e a tecnologia, aliadas aos conhecimentos profissionais especializados, oferecem oportunidades, compensa perdas, facilita adaptaçóes às mudanças, recupera capacidades perdidas, melhorar níveis de segurança no meio ambiente, enfim, assegura ao ser humano alguma condição de vida satisfatória, até idades avançadas. $\mathrm{O}$ acesso a esses recursos, entretanto, passa pelo crivo da desigualdade social, face ao ritmo acelerado das mudanças e dos desencaixes produzidos pela sociedade moderna (GIDDENS, 1996).A respeito da questão educacional, Moacir Carneiro (2002), comenta:

\begin{abstract}
"O extraescolar representa um canal importante para abrir espaços de articulação, pela possibilidade de construir um conteúdo de ensino capaz de 'satisfazer as necessidades de aprendizagem'." Acrescenta ainda que "o extraescolar náo é a subeducaçăo. Pelo contrário, o extraescolar é o trabalho, a convivência, o lazer, a família, o amor, a festa, a igreja, (...), a vida, enfim".
\end{abstract}

Reconhecemos a relevância do pensamento desse autor quanto à valorização do extraescolar que, em certa escala, corresponde ao ensino não formal, por isso o mencionamos como comentarista da LDB. É também esclarecido por Ivani Piton(2005), que:

Educação Não Formal acontece em torno de políticas ou propostas de inclusão social (nestes casos através do Terceiro Setor, ONGs, Sindicatos, Fórum, Fundaçôes, Pastorais, Voluntariado, etc.). Ou voltada à melhoria da qualidade de vida da populaçáo (propostas educacionais, artísticas, culturais e corporais voltadas para o atendimento de crianças, jovens, adultos e velhos fora do contexto da educação formal, etc.). Ou seja, a Educação Não Formal se dá principalmente em contexto educativos não escolares, ou escolares, mas não formais.

Os campos da Educação Não Formal podem ser agrupados nos seguintes objetivos:

a) alfabetizar ou transmitir conhecimentos abrangendo a área que se convencionou chamar de educação popular (anos 70/80) e educação de jovens e adultos (anos 90);

b) abrange a educação gerada no processo de participação social, em açôes coletivas não voltadas para os conteúdos formais; (GOHN, 2001).

Conforme Mercadante (2003), a construção da "terceira idade" representa para os idosos um critério importante de autoclassificação, pois muitos não se sentem incomodados com a categoria atribuída. Hoje já podemos dizer que o idoso está conquistando o seu papel na sociedade e encontrando satisfaçáo durante o processo de envelhecimento, porém, aquele que convive com a carência de políticas 
públicas sociais adequadas tem dificuldade de se estabelecer como sujeito de direitos na sociedade, tornando o envelhecimento um pesadelo, por sofrer diretamente de preconceitos e mitos responsáveis pela exclusão deste segmento. A estratégia na implementação, conscientização e mobilização do poder público e da sociedade civil em torno das possibilidades da Educação Não Formal é amplo e está ligado ao conceito de cultura política e de educação social, daí decorre a necessidade do envolvimento do maior número possível de entidades e de pessoas com conhecimento voltado ao envelhecimento. Nos últimos anos, a gerontologia vem se firmando na busca de estabelecer-se como ciência do envelhecimento, e em sua concepção mais ampla, é marcada por atividade de natureza técnica e multidisciplinar, se relaciona com a pesquisa científica, na produção de conhecimento por meio de ciências que têm o ser humano que envelhece como seu objeto de estudo. A literatura discute conceitos e enfatiza o que é importante para se obter um envelhecimento saudável, levando em consideraçóes aspectos como:

- Baixo risco de doenças e de incapacidades funcionais;

- Funcionamento mental e físico excelente;

- Envolvimento com a vida;

- Situaçóes sociais, educacionais e financeiras.

Nesse aspecto, Mascaro (2004), nos mostra que o idoso mantém o desejo de viver intensamente sua própria vida, de realizar novos projetos de vida, de não sucumbir aos preconceitos e estereótipos. Há necessidade de refletir a função do idoso e sua contemporaneidade para despertá-lo sobre a necessidade de construir um projeto para sua vida que lhe confira significado, valorizando sua capacidade de criar, sonhar e desejar. (BRUNO, 2003).

House (1981 apud Ramos, 2002) e Cockerham (1991), observam que os benefícios do apoio familiar na saúde dos idosos e as relaçóes sociais podem ter um papel essencial para promover a saúde física e mental. Quando os efeitos positivos do suporte social estão associados com a utilidade de diferentes tipos de suporte fornecidos pela família (emocional ou funcional), é esperado que pessoas idosas sintam-se amadas, sintam-se seguras para lidar com problemas de saúde e tenham alta autoestima (CICIRELLI, 1990). As redes sociais formadas por familiares e amigos significativamente abalam os efeitos do estresse nos indivíduos mais velhos. Elas oferecem suporte social na forma de amor, afeição, preocupação e assistência (COCKERHAM, 1991).

Orth-Gomer e Johnson, (1987), comentam que pessoas que não têm este tipo de suporte tendem a ter mais dificuldade para lidar com o estresse que aquelas pessoas que têm o suporte social. Normalmente, a ausência de parentes, especificamente parentes mais próximos tais como o côn- juge ou os filhos, está associada com doença e mortalidade entre pessoas idosas. Um dos efeitos positivos exercidos pela família na saúde dos idosos está relacionado ao fato de que este suporte tende a reduzir os efeitos negativos do estresse na saúde mental.

\section{OBJETIVO GERAL}

Neste trabalho temos como objetivo principal apresentar, no formato de relato de experiência, uma cartilha educativa com conceitos de ciências, saúde e cidadania a partir do perfil e concepções sobre o processo de envelhecimento e as etapas da vida entre idosos participantes dos grupos de convivência do município de Volta Redonda-RJ.

\section{Objetivos Específicos}

- Realizar, por meio do instrumento de coletas de dados, um mapeamento quantitativo dos idosos que frequentam os grupos estudados, de modo a identificar condiçôes sócio-econômicas, recortes de renda e localização geográfica.

- Verificar de forma qualitativa as concepçóes que os idosos compartilham sobre envelhecimento e as etapas da vida, entre outros; (segue anexas duas perguntas que ainda estão em avaliação).

- Elaborar uma cartilha, com as questôes que mais afligem os idosos, para ampliar na prática de açôes e informaçóes nos grupos de convivência e que subsidie os profissionais que trabalham diretamente com os idosos em espaço de ensino não formal. (segue anexo o protótipo).

\section{METODOLOGIA}

O participantes deste projeto são idosos que frequentam os 40 Grupos de convivência da Secretaria Municipal de Ação Comunitária - SMAC de Volta Redonda- RJ. A primeira etapa da pesquisa foi a aplicação do instrumento de coleta de dados de forma amostral (10\% do número total de idosos participantes dos grupos de convivência), com 400 idosos, na intenção de mapear o perfil sócio-econômico de tais idosos. Foram elaboradas questóes relativas à participação nos grupos de convivência, a saber: Quantos idosos moram sozinhos e/ ou com quem? Em que situação financeira? O que os levou a procurar o grupo?Em qual bairro da cidade existe mais citação de violência e maus tratos? Entre outras situaçôes. 
Em uma segunda etapa será solicitado a 3 idosos, um em cada perfil de renda entre, 1 a 2/, 3 a 4/ e com mais de 5 salários mínimos por grupo que queiram participar, para uma avaliação qualitativa com questóes em torno dos temas envelhecer, etapas da vida e das categorias sociais, idade e velhice.

Pretendemos pontuar na cartilha os assuntos em tópicos para uma sequencia de discussão e que seja uma junção e possibilite a integração das outras já existentes, facilitando o conhecimento.

\section{O PERCURSO NA CONSTRUÇÃO DA CARTI- LHA PARA IDOSOS}

Para se chegar à construção do protótipo da cartilha, iniciamos com as observaçóes e anotaçôes das ações realizadas nos encontros diários, como nas dinâmicas, nos relatos das concepçóes de envelhecimento, que permitiram reflexóes e discussóes nos grupos que mais chama a atenção dos idosos em relação ao envelhecimento. As questôes, promoção social (direitos, dignidade) e qualidade de vida (saúde, maus tratos e violência), foram citadas no geral. $\mathrm{Na}$ aplicação do $1^{\circ}$ modelo do instrumento de avaliação, levantamento aplicaçáo do $2^{\circ}$ modelo do instrumento de avaliaçáo, percebeu-se que seria necessário ampliar, fechar todas as perguntas e criar um programa computacional para nos estruturar na compilação dos dados para melhor buscar relatórios específicos.

Os resultados iniciais mostram como o primeiro questionário pensado foi com base exclusivamente em questóes sócio-econômicas, foi posteriormente verificada a necessidade de ampliar para conhecer questóes como: Doenças pré-existentes, renda individual e renda familiar (per capta). Após as etapas, observou-se que muitos idosos têm um salário mais alto e estável, uma grande parcela tem casa própria, contribuem significativamente na renda familiar e, em muitos casos, os filhos moram na mesma residência. $\mathrm{O}$ trabalho também demonstra que a vulnerabilidade financeira se associa a questão educacional e é mais evidende no sexo feminino. A aposentadoria é fator relevente na questão financeira.

Com base na prática do trabalho diário, com observaçôes dos relatos e com reflexôes já realizadas nos grupos de convivência, o que mais aparece são as questôes como: Direito e dignidade; Saúde, maus tratos e violência doméstica. Diariamente, anotamos o que aflige os idosos nas discussóes. Então, esboçamos um protótipo de cartilha com questóes básicas observadas nos relatos, que posteriormente será avaliado para conclusão e futuramente criação da cartilha em um formato que mais atenderá as perspectivas dos idosos.

É necessário que a cartilha: atenda nas informaçóes mais desejadas aos idosos, subsidie as pessoas que lidam di- retamente com grupos de convivência de idosos, dinamize mais o trabalho, oportunize mais conhecimentos, dignidade e cidadania.

\section{CONSIDERAÇÓES FINAIS}

São diversos os desafios trazidos pelo envelhecimento da população, uma vez que tal mudança na pirâmide etária influencia o consumo, o mercado de trabalho, assistência médica e assistência social, entre outros.

Neste trabalho, pretendemos conhecer as opinióes dos idosos sobre o seu próprio envelhecimento e seu desenvolvimento biopsicosocial, suas formas e processos, permitindo assim ampliar as variáveis em encontro com um envelhecimento saudável, contribuindo para melhorar a qualidade e eficácia do atendimento às necessidades da população idosa.

Observamos que existem muitas cartilhas em separado, como a Cartilha do Ministério da Saúde, Ministério da Previdência Social, UERJ e OAB, mas pretendemos pontuar nesta cartilha os assuntos em tópicos para uma sequência de discussão. Dessa forma, entendemos que a cartilha será um instrumento importante para aumentar a autonomia dos idosos e dos profissionais que atuam diretamente nos grupos de convivência, para um melhor diagnóstico e planejamento das açóes com os grupos.

\section{REFERÊNCIAS}

ALMEIDA, Vera Lúcia Valsecchi de (2003) Modernidade e velhice. In: Revista Serviço Social e Sociedade, São Paulo, Cortez, no 75, p.35-54.

BARBOSA, R.M. dos S.P. Educação física gerontológica. Rio de Janeiro: Sprint, 2000.

BARRETO, M.L. 1992. Admirável mundo velho - velhice, fantasia e realidade social. Ática, São Paulo, 237pp.

BARROSO, M. Um Resgate Histórico da Gerontologia e do Trabalho Social com Idosos no Brasil. A Terceira Idade, São Paulo, SESC, ano XII, n. 22, p. 68-84, jul., 2001.

BEAUVOIR, S. 1976. A velhice: realidade incômoda. (2a ed.).DIFEL, São Paulo 339pp.

BOSI. E. 1983. Memórias e sociedade: lembranças de velhos. T.A. Queiroz, São Paulo, 405pp. 
BERQUÓ, E. Considerações sobre o Envelhecimento da população no Brasil. In: NERI, A. L. DEBERT, G. G. (orgs.). Velhice e sociedade. Campinas, SP: Papirus, 1999.

BERZINS, Marília Anselmo Viana da Silva (2003), Envelhecimento populacional: uma conquista para ser celebrada. In: Revista Serviço Social e Sociedade, São Paulo, Cortez, no 75, p. 19-34.

BRUNO, Marta Regina Pastor, Cidadania não tem idade. In: Revista Serviço social e sociedade.São Paulo, Cortez, p.74-83.

CARVALHO, R. B. da C. Perfil de aptidão física relacionada à saúde de pessoas a partir de 50 anos praticantes de atividades físicas. Dissertação de Mestrado, Faculdade de Educação Física, Universidade Estadual de Campinas, Campinas: [s.n], 2003.

CA R N E I RO, M. A. LDB Fácil - Leitura crítico - compreensiva artigo a artigo. Editora Vozes, Petrópolis, 8a. edição, p. 39. 2002.

CICONELLI, R. M. Tradução para o português e validação do questionário genérico de avaliação de qualidade de vida 'Medical Outcomes Study 36-item short form Health Survey (SF-36)'. Tese (Doutorado), Escola Paulista de Medicina, Universidade Federal de São Paulo, São Paulo, 1997.

CICIRELLI,V.G.Family support in relation to healt problems of the elderly.In T.H.Brubaker (ed.),Family relationships in later life.2ºd. Newbury Park,CA: Sage,p.212-228.

COCKERHAM,W.This aging society. New Jersey: PrenticeHall,1991.

COUTO, Maria Clara Pinheiro de Paula (2005), Fatores de Risco na promoçáo de Resiliência no Envelhecimento. Projeto de dissertação.UFRGS, Porto Alegre.

CUPERTINO, Ana Paula Fabrino Bretas, ROSA, Fernanda Heringer Moreira e RIBEIRO, Priscila Cristina Correa. Definiçáo de envelhecimento saudável na perspectiva de indivíduos idosos. Psicol. Reflex. Crit. [online]. 2007, vol. 20, no.1[citado],pp.8186. Disponívelem<http:// www.scielo.br/scielo.php?script=sci_arttext \&pid=S0102$79722007000100011 \& \operatorname{lng}=p t \& n r m=i s o>$. ISSN $0102-$ 7972. DOI: 10.1590/S0102-79722007000100011
DEBERT, G.G. 1998. A antropologia e o estudo dos grupos e das categorias de idade, pp. 49-67. In Lins de Barros M.M (org.). Velhice ou terceira idade? Estudos antropológicos sobre identidade, memória e política. Fundação Getúlio Vargas, Rio de Janeiro.

(2004). A Reivenção da Velhice: socialização e processos de reprivatização do envelhecimento. São Paulo: Edusp/FAPESP, 266p.

FORTI, V.A.M.; CHACON-MIKAHIL, M.P.T. “Qualidade de Vida e Atividade Física na terceira idade". In: GONÇALVES A., VILARTA, R. Qualidade de Vida e Atividade Física: explorando teoria e prática. Barueri: Manole, 2005: p. 227-256

FREIRE, S.A. "Envelhecimento bem sucedido e bemestar psicológico”. In: NERI, A.L.,

FREIRE, S.A. E por falar em boa velhice. Campinas: Papirus, 2000: p.21-31.

GALLO JR., L. et al. Atividade física: "remédio cientificamente comprovado?" A terceira idade, Editora SESC, ano VI, n. 10, 1995.

GIDDENS, A. As conseqüências da modernidade. São Paulo: UNESP, 1996.

GOBBI, S. "Atividade Física para Pessoas Idosas e Recomendaçóes da Organizaçáo Mundial de Saúde de 1996” in Revista Brasileira de Atividade Física e Saúde. v. 2, n. 3, 1997: p. 41-49.

GOHN, Maria da Glória. Educação Não-Formal e Cultura Política. São Paulo: Cortez, 2001.

HADDAD E.G.M 1986. A ideologia da velhice. Ed. Cortez, São Paulo. 135pp.

1993. O direito à velhice: os aposentados e a previdência social. Ed. Cortez, São Paulo, 115pp. (Coleção Questôes da Nossa Época).

INSTITUTO BRASILEIRO DE GEOGRAFIA E ESTATÍSTICA. Perfil dos idosos responsáveis pelos domicílios no Brasil 2001/IBGE, Departamento de População e Indicadores Sociais. Rio de Janeiro: IBGE, 2002. p. 11-12. 
MASCARO, Sonia de Amorim (2004), O que é velhice. $2^{\circ}$ ed, São Paulo, Brasiliense, (Coleção Primeiros Passos; 310).

MEDEIROS, S. A. R. Como pensar a vida. Revista Serviço Social e Sociedade, São Paulo, v. 75, p. 1-208, 2003.

MERCADANTE, E. Aspectos Antropológicos do Envelhecimento. In: PAPALÉO NETTO, M. Gerontologia. A velhice e o envelhecimento em visão globalizada São Paulo: Editora Atheneu, 1996. p.73-76

NERI, A.L. "Qualidade de vida no adulto maduro: interpretações teóricas e evidências de pesquisa” in NERI, A. L. (Org.). Qualidade de vida e idade madura. Campinas: Papirus, 1993. V $1.285 \mathrm{pp}$.

Psicologia do Envelhecimento: temas selecionados na perspectiva de curso de vida. Campinas - S.P. : Papirus, 1995. V 1. 276 pp.

"Velhice e qualidade de vida na mulher" in NERI, A. L. (Org.). Desenvolvimento e envelhecimento: perspectivas biológicas, psicológicas e sociológicas. Campinas: Papirus, 2001: V 1. 200 pp.

PINHEIRO, D. P. N. Resiliência em Discussão. Psicologia em estudo, Maringá, v.9, n.1, p.67-75, 2004.

PRADO, Shirley Donizete and SAYD, Jane Dutra. A gerontologia como campo do conhecimento científico: conceito, interesses e projeto político. Ciênc. Saúde coletiva, Apr./June 2006, vol.11, no. 2, p.491-501. ISSN 1413-8123

RAMOS, Marília P. Apoio Social e Saúde entre Idosos. Sociologias, Porto Alegre, n. 7, 2002. Disponível:<http:// www.Scielo.br/scielo. Php?Script=sci_arttext\&pid=S1517$45222002000100007 \& \operatorname{lng}=e n \& n r m=i s o>$. Acesso em: 20 Apr 2008. doi: 10.1590/S1517-45222002000100007

SALGADO, M. A. Velhice, uma nova questão social. São Paulo: SESC-CETI, 2a edição, 1988. 121pp.

VERAS R.P. 1994. Pais jovens com cabelos brancos: a saúde do idoso no Brasil. (2a ed.). Relume Dumará-UERJ, Rio de Janeiro, 225pp.

YUNES, M. A. M. \& Szymanski, H. (2001). Resiliência: noçáo, conceitos afins e consideraçóes críticas. Em J.Tavares (Org.), Resiliência e educação (pp.1342). São Paulo: Cortez.

Endereço para Correspondência:

Rosane Marques de Carvalho rosane@ioc.fiocruz.br Mestrado Profissional em Ensino em Ciências da Saúde e do Meio Ambiente

Centro Universitário de Volta Redonda Campus Três Poços Av. Paulo Erlei Alves Abrantes, no 1325 , Três Poços - Volta Redonda / RJ CEP: 27240-560 